\title{
A rare case of fetus papyraceous presenting in monozygotic biamniotic twins
}

\author{
Lakshmi S.*, Rajkumar K.
}

Department of Gynecology and Obstetrics, NTC Hospitals Kizhavaithiyanathapuram Thathaneri Main Road, Madurai, Tamil Nadu, India

Received: 07 November 2019

Accepted: 03 December 2019

\section{*Correspondence:}

Dr. Lakshmi S.,

E-mail: lakmisubburaj@gmail.com

Copyright: (C) the author(s), publisher and licensee Medip Academy. This is an open-access article distributed under the terms of the Creative Commons Attribution Non-Commercial License, which permits unrestricted non-commercial use, distribution, and reproduction in any medium, provided the original work is properly cited.

\begin{abstract}
Fetus papyraceous or compresses is characteristic of compressed mummified, parchment like remains of dead twin retained in utero after intrauterine death in the second trimester. It is an uncommon finding and we report in a G2P1L1 with 22 weeks with Monozygoticbiamniotic twins with fetus papyraceous stuck to left upper segment followed up to 36 weeks. The mother was advised regular antenatal visits and frequent feto-maternal monitoring was done. Patient delivered a single live baby and a placenta with mummified fetus within it. The incidence of fetus papyraceous is about 1 in 17000 to 1 in 20000 pregnancies. Early diagnosis of this condition helps in monitoring the surviving fetus.
\end{abstract}

Keywords: Fetal monitoring, Fetus papyraceous, Monochorionic twins, Twin emobolization syndrome

\section{INTRODUCTION}

Fetus papyraceous or compresses is the compressed, mummified parchment like remains of a dead twin which is retained in utero after intrauterine death in the second trimester. ${ }^{1-3}$ Although early diagnosis has become possible due to newer modalities, many a time, it was diagnosed as a post-delivery sequence on examining the placenta. The incidence of fetus papyraceous has been reported in 1 in 17,000 to 20,000 pregnancies. $^{3}$ This intrauterine accident occurs in 1 in 184 twin pregnancies $(0.54 \%)$ and in about 1 in 8000 triplet pregnancies. ${ }^{4}$

The hazards of fetus papyraceous are predominantly seen on the surviving twin. The surviving twin is at risk of twin embolization syndrome. Twin embolization syndrome is often seen in monozygotic twinning following in utero demise of the co-twin. It results from embolization of placentary and fetal thromboplastins or necrosed elements of placenta from dead fetus causing embolization. ${ }^{5}$ Thereby resulting in ischemia and necrosis of major organs. Therefore, careful monitoring is mandatory. ${ }^{6}$ In this case report, we present a rare case of fetus papyraceous detected during 22 weeks gestation and followed up to a healthy surviving twin delivered at term.

\section{CASE REPORT}

G2P1L1 with 22 weeks gestation with previous LSCS came for routine antenatal check-up. Patient had regular cycles and had nil significant history. Patient's general condition was good and on examination per abdomen uterus was corresponding to 20 weeks of gestation and fetal parts were felt. All the routine investigations and ultrasound were performed.

Ultrasound examination revealed monozygotic biamniotic twins with fetus papyraceous stuck to left upper segment of the placenta. The other fetus was corresponding to 22 weeks of gestation. All other 
parameters were normal. Patient was counseled about the risk of embolization and counseled.

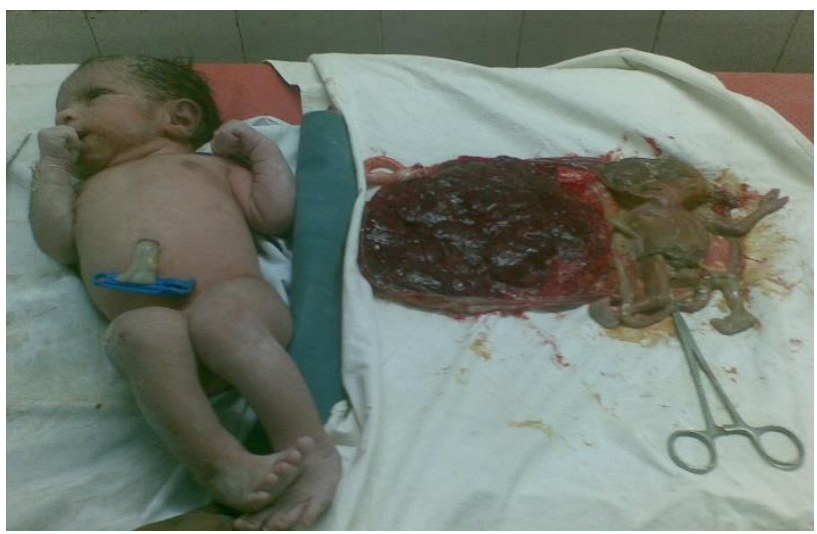

Figure 1: Normal baby with papyraceous fetus of twin gestation.

Patient was reviewed during every checkup and followed up with serial ultrasound and coagulation profiles. At 38 weeks patient presented with labor pains. Repeat LSCS was indicated because of fetal distress and a single live baby weighing 2.9 kilograms was delivered. On examination baby was normal. Placenta with mummified fetus within it was, delivered in to. The placenta was mono chorionic diamniotic with parchment like fetus stuck to it (Figure 1). The Apgar was normal. The mother had a normal puerperium and was discharged on fifth day.

\section{DISCUSSION}

The antenatal diagnosis of single fetal demise has become more common following frequent use of ultrasound in earlier gestation. The diagnosis of single fetal demise poses pressure on family, patient and doctors as it is impossible to predict all the complications. ${ }^{7}$ To date a first trimester intrauterine demise does not have adverse effect on the surviving twin. In second and third trimester it becomes little complex.

In case of monochorionic twins the prognosis is poor and is associated with neurological damage in the survivor. ${ }^{8}$ This is mainly due to the placental vascular connections in the monochorionic twins. The presence of vascular anastomosis might lead to vascular disruption injury. If it occurs in early pregnancy it would result in atresia or selective tissue loss. If it occurs in later gestation, it will result in tissue infarct and cystic changes.

Single intrauterine death also causes elevated alpha fetoprotein levels in the surviving twin. Fetus papyraceous has also been reported to be a cause of dystocia if the dead fetus lies transversely in the pelvis below the presenting part of the surviving twin. ${ }^{9}$

The chorion city and zygosity should be determined by earlier ultrasound as these are the predicting factors for prognosis and preferably, they should be followed up at tertiary centres where monitoring facilities and good neonatal support is available.

\section{CONCLUSION}

We have presented a case report of a rare condition which warrants careful evaluation of mono chorionic pregnancies. However, management depends on the gestational age and placentation. Careful monitoring preferably in centres equipped with all facilities is needed. Conservative management is preferred weighing the risks versus benefits and decision should be individualized for each case. Evaluation, counselling and meticulous follow up are mandatory.

\section{Funding: No funding sources \\ Conflict of interest: None declared \\ Ethical approval: Not required}

\section{REFERENCES}

1. Donald I. Twins. In: Practical obstetric problems. Lloyd-Luke, London; 1979:359-377.

2. Fisk NM. Multiple Pregnancy. In: Edmonds DK (ed). Dewhurst's textbook of obstetrics and gynaecology for postgraduates. Blackwell, Oxford; 1999:298-307.

3. Bush M, Pernoll ML. Multiple pregnancy. In: DeCherney AH, Nathan L (eds). Current obstetric and gynecologic diagnosis and treatment. McGraw-Hill, New York; 2003:315-325.

4. Mittal P, Khanna M. Two papyraceous fetuses in a triplet pregnancy. J Obstet Gynaecol India. 2007;57:778.

5. 5. Pattern RM, MackLA, Nyberg DA, Filly RA. Twin embolization syndrome:prenatalsonographic detection and significance.Radiology 1989;173(3):685-689.

6. Rasheed F, Amjad N. Case report, fetus papyraceus: rarity among rarities. Ann. 2008;14(4):154-5.

7. Enbom JA. Twin pregnancy with intrauterine death of one twin. Am J Obstet Gynecol. 1985:152:424-9.

8. Fusi L, Gordon H. Twin pregnancy complicated by single intrauterine death. Problems and outcomes with conservative management. $\mathrm{Br} \mathrm{J}$ Obstet Gynecol. 1990;97:511-6.

9. Leppert P, Wartel L, Lowman R. Fetus papyraceous causing dystocia: inability to detect blighted twin antenatally. J Obstet Gynecol. 1979;54:381-3.

Cite this article as: Lakshmi S, Rajkumar K. A rare case of fetus papyraceous presenting in monozygotic biamniotic twins. Int J Reprod Contracept Obstet Gynecol 2020;9:448-9. 